\title{
Harmonics Assessment in Real Time Printing Industry
}

\author{
D. Ravichandran, K.Saravanan, Utkarsh Bajpai, Ganesh Ramakrishnan, Aparajit Vasudevan, \\ Anna Chacko, Shivam Khare
}

\begin{abstract}
The harmonics assessment in every industry is necessary for the reliability and quality of the product. In this paper the harmonic measurement in a printing industry, which is done by the instrument in accordance with IEC 61000-4-7 is presented. The harmonics level in various circuit conditions considered and explained in this paper. The permitted level of which are verified with IEEE 519 - 1992 and the richness of the harmonics are highlighted. The Total Harmonics Distortion and Individual Harmonics Distortion are measured at specified locations in the consumer distribution network with four different circuit conditions. The power factor varaiation due to change in the circuits also highlighted in this paper. This paper gives wide scope for readers to understand the typicality of the harmonics pattern and it's interaction with consumer distribution network.
\end{abstract}

Index Terms- Total Harmonics Distortion, Individual Harmonics Distortion, Power Factor, Harmonic Analysis, Printing Industry

\section{INTRODUCTION}

The printing industry has seasonal varaiations in energy consumption and different harmonics charcateristics of load demanded by the processes. It includes exclusive processes such as offset printing, glueing, folding, lamination, pinning and packing etc., The utility is levying charges for low power factor compensation and demand charges for exceeding permitted demand. Hence the industry needs to monitor the average power factor and to maintain 0.98 by power factor controllers. Ineraction of these capacitors with harmonics at PCC are also presented in this paper, furthermore the utility is notifed of the harmonics distortion with variation of the load at the MV bus if it exceeds the limit imposed. The industry uses harmonic filters to bring down the level of distortion to that recommended by the utility. The interaction of the filter at various operating conditions of the plant is observed. This paper helps the user find the Total Hormonics Distortion level, Individual Harmonics Distortion at maximum THD and the pattern of harmonics corresponding

Revised Version Manuscript Received on 10 September, 2019.

D. Ravichandran, Assistant Professor, SRM Institute of Science and Technology, Kattankulathur, Chennai, Tamil Nadu, India.

Dr.K.Saravanan, Associate Professor, Institute of Science and Technology, Kattankulathur, Chennai, Tamil Nadu, India.

Utkarsh Bajpai, Students of Dept. of EEE, SRM Institute of Science and Technology, Kattankulathur, Chennai, Tamil Nadu, India.

Ganesh Ramakrishnan, Students of Dept. of EEE, SRM Institute of Science and Technology, Kattankulathur, Chennai, Tamil Nadu, India.

Aparajit Vasudevan, Students of Dept. of EEE, SRM Institute of Science and Technology, Kattankulathur, Chennai, Tamil Nadu, India.

Anna Chacko, Students of Dept. of EEE, SRM Institute of Science and Technology, Kattankulathur, Chennai, Tamil Nadu, India.

Shivam Khare, Students of Dept. of EEE, SRM Institute of Science and Technology, Kattankulathur, Chennai, Tamil Nadu, India. to the load, furthermore, it also helps validate the THD corresponding to loading with respect to IEEE 519 - 1992.

\section{POWER SYSTEM}

\section{A. Description of Power System}

The Industry's outdoor sub-station has $11 \mathrm{kV}$ power supply from a utility grid. An outdoor transformer of $11 \mathrm{kV} /$ $433 \mathrm{~V}, 500 \mathrm{kVA}$ transformer connected to a MV indoor Sub-station where a number of feeders are connected to various loads such as composite loads harmonics loads, capacitor loads and active filters as shown in Fig.1, 100 kVAR capacitors are used to improve power factor. Composte loads of $320 \mathrm{~kW}$ are used for

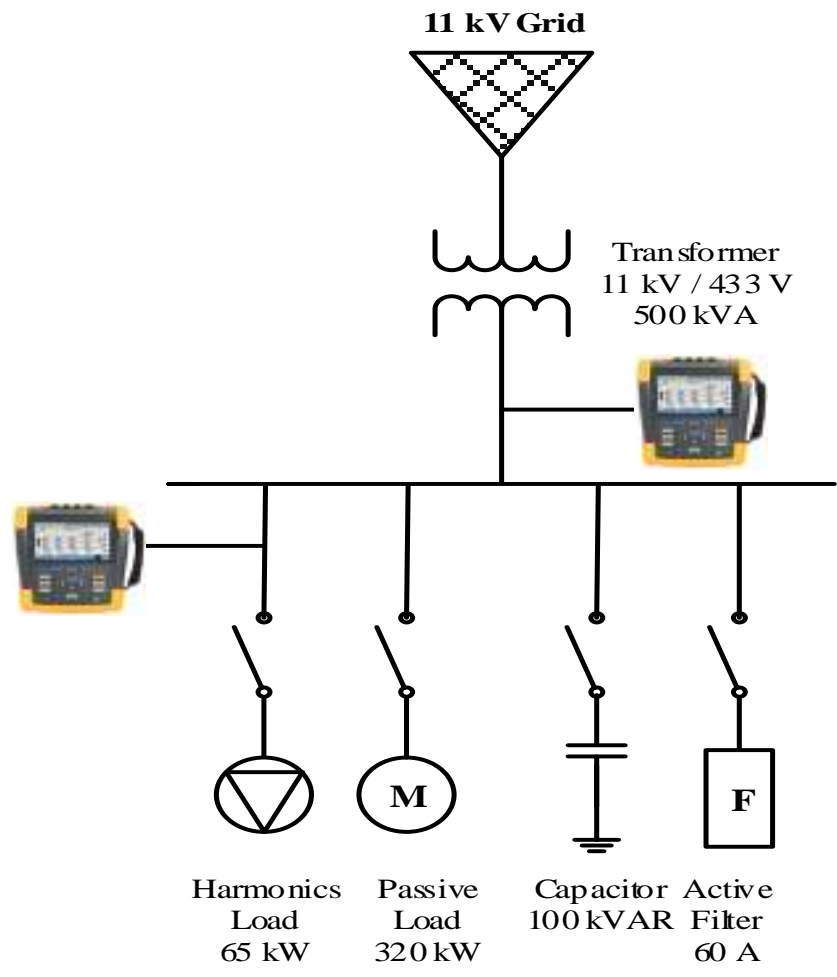

Fig.1 Single Line Diagram 
various machines and static loads. Harmonics load of $65 \mathrm{~kW}$ is used for offset printing and other allied processes. An active filter, rated $65 \mathrm{~A}$ is used for filtering harmonics.

\section{B. Description of circuit Conditions}

Harmonic measurement was done using a Fluke 434 Series 2 Power Quality and Energy Analyser. The harmonic measurement was done at two points in the industry. The meter was connected in two different locations (i.e. M.V. side of substation and individual harmonics loads) The data logged are V (rms), I (rms), THD, IHD, Power Factor, and $\%$ Unbalance. The measurement is done in all four test conditions (as in Table.1) in respective interval of measurement. The measurement is taken for every 10 seconds.

\section{Table.1 Circuit condition}

\begin{tabular}{|l|l|l|}
\hline Circuit Condition & $\begin{array}{l}100 \\
\text { Capacitor }\end{array}$ & $\begin{array}{l}60 \text { A Harmonics } \\
\text { Filter }\end{array}$ \\
\hline 1 & ON & ON \\
\hline 2 & OFF & ON \\
\hline 3 & ON & OFF \\
\hline 4 & OFF & OFF \\
\hline
\end{tabular}

The harmonics measurements are calculated from 10/12 cycles harmonic group measurements on Voltage and Amps according to IEC 61000-4-7.

The voltage unbalance is evaluated using the method of symmetrical components according to IEC 61000-4-30

\section{HARMONICS ASSESSMENT IN CIRCUITS}

Circuit Condition: 1

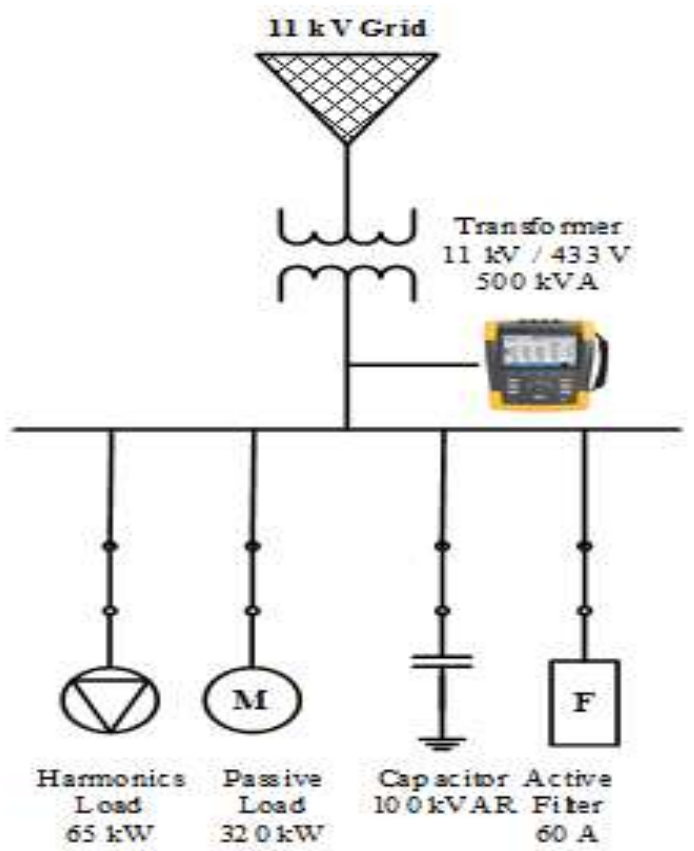

Fig.2 Single Line Diagram ( Circuit Condition -1)

The measurements are taken at the LV side of transformer. All the loads which are $\mathrm{ON}$ are considered as condition -1 . The measurements on power factor, THD for current and voltage and IHD for the correspondting THD are taken. The waveform for voltage and current are also shown in Fig. 6.
The phase colours used are Red, Yellow and Blue for the reference. In spectrum plot, the $100 \%$ fundamental is removed for clarity of displaying other individual harmonics. The harmoncs order 0 is considered as DC quantity in harmonics spectrum format.

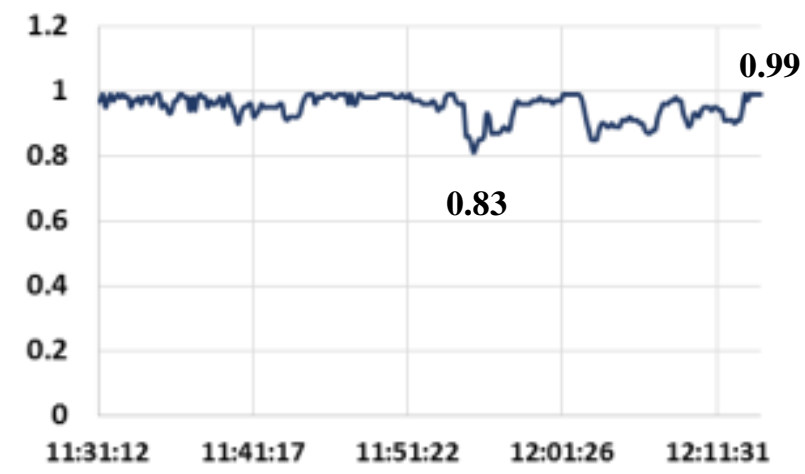

Fig 3. Power factor trend in Circuit - 1

The average power factor varies between 0.83 and 0.99 due to power factor controller. The utility is recording the average power factor for the assessment period of one month. The average power factor over a period may get maintained if the correction is appropriate.

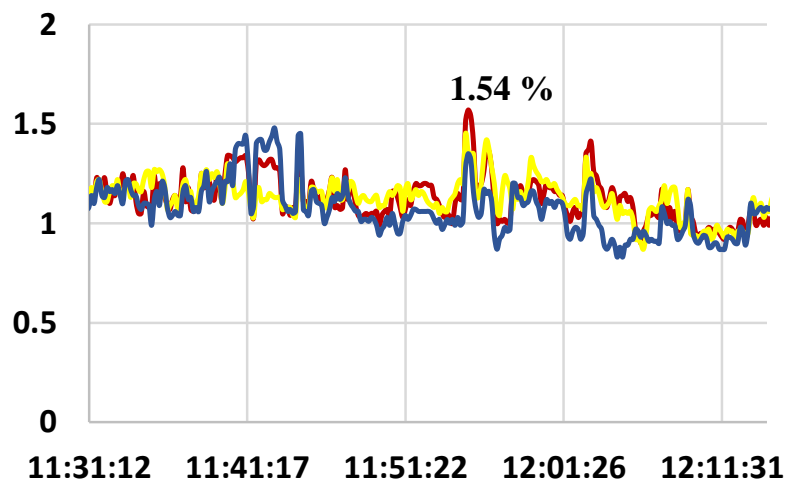

Fig 4. Voltage THD trend in circuit - 1

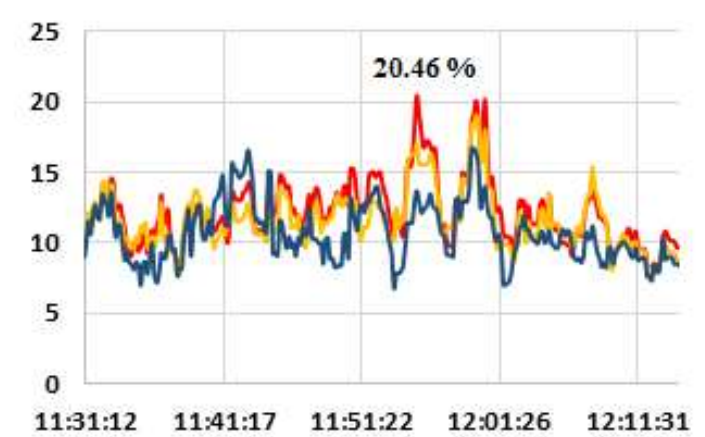

Fig 5. Current THD trend in circuit - 1 


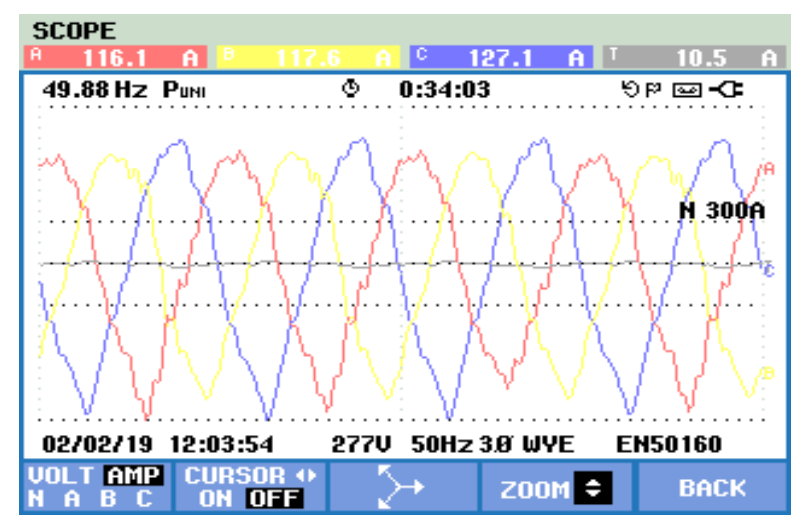

Fig 6. Three-phase Current waveforms in circuit - 1

The distorted current waveforms in the three-pahses are obtained as above for the THD of $20.46 \%$ ( $\mathrm{R}-\mathrm{Phase})$. The voltage THD recorded as low as $1.54 \%$. The $\mathrm{R}-$ phase predominantly has THD in both voltage and current harmonics as shown in Fig. $4 \& 5$. The individual harmonics distortion with respect to the corresponding occurrence of THD for voltage current are shown below. The current THD $20.46 \%$ is observed high and needs to be validated with IEEE 519-1992.

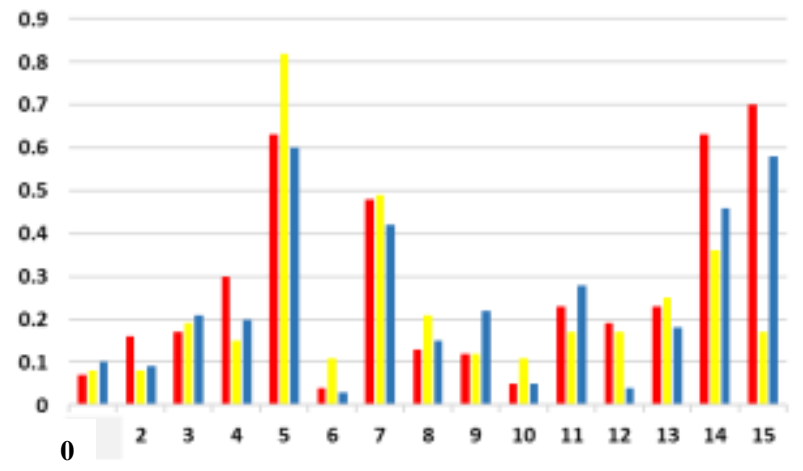

Fig 7. Voltage harmonics spectrum for circuit - 1

The voltage harmoncs order of $2,3,4,5,7,9,11,14$ and 15 predominantly above $0.1 \%$ high comparing other harmonics.

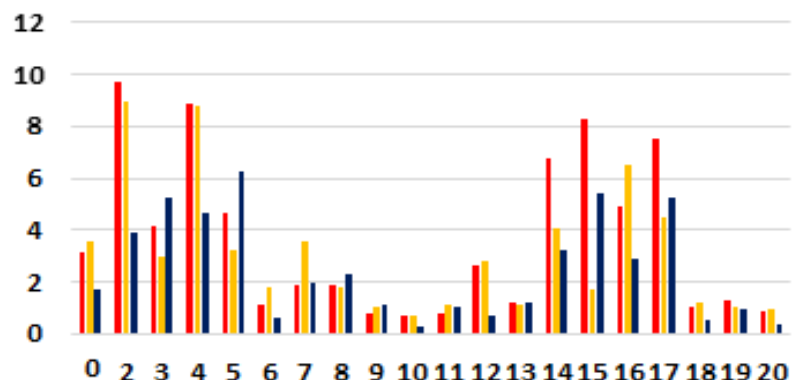

Fig 8. Current harmonics spectrum for circuit - 1

The current harmonics order of 2, 3, 4, 5, 7, 14, 15, 16, 17 predominantly above $4 \%$ high comparing other harmonics.

\section{Circuit Condition: 2}

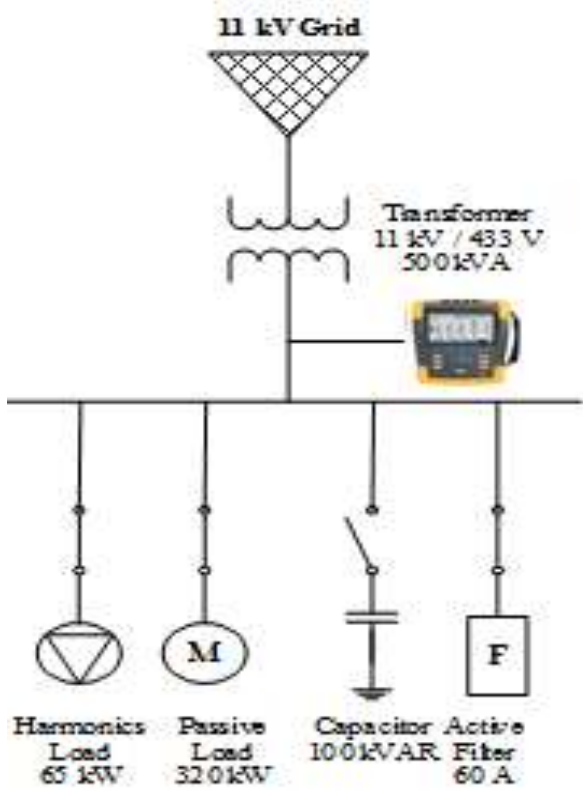

Fig.9 Single Line Diagram ( Circuit Condition -2)

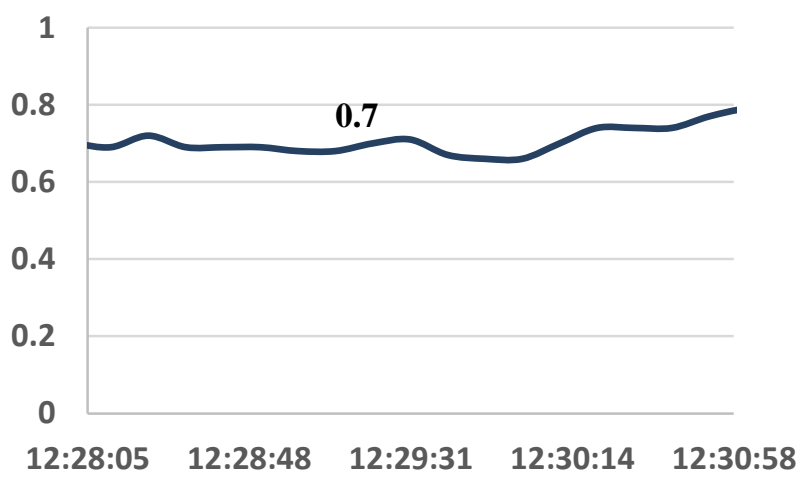

Fig 10. Power factor trend in circuit - 1

The power factor is reduced from 0.99 in circuit -1 to 0.8

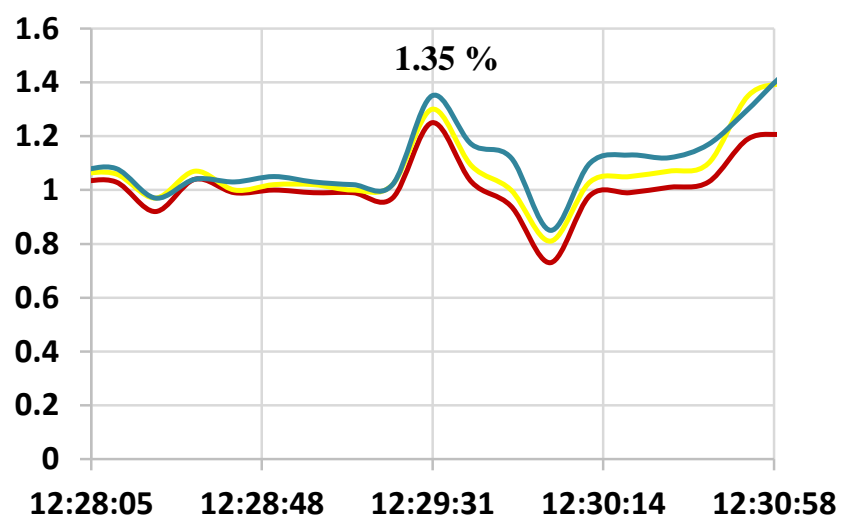

Fig 11. Voltage THD trend in circuit -2 


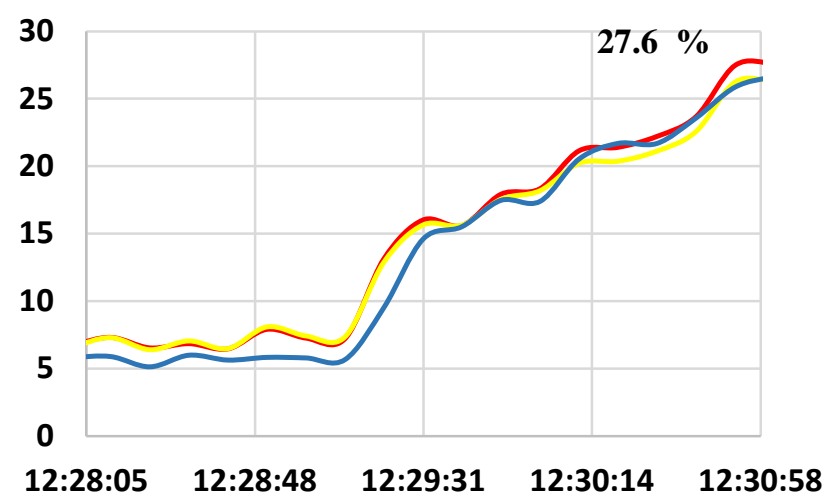

Fig 12. Current THD trend in circuit -2

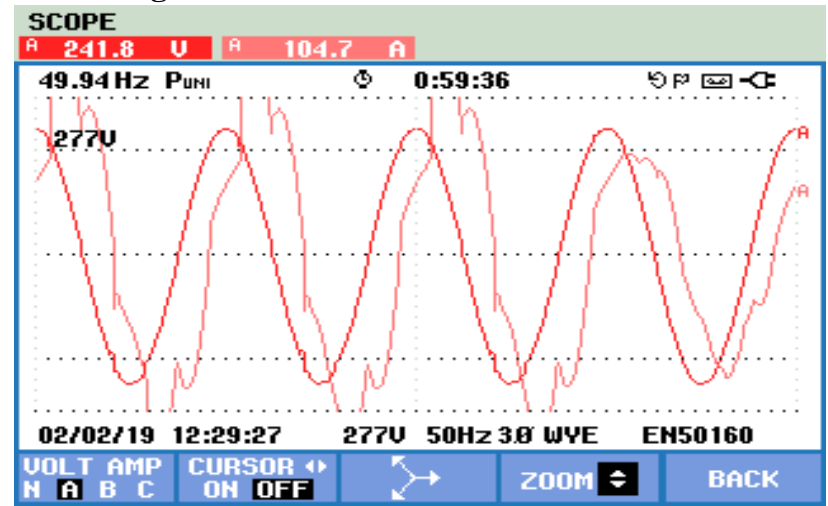

Fig 13. Voltage and Current waveform in circuit - 2

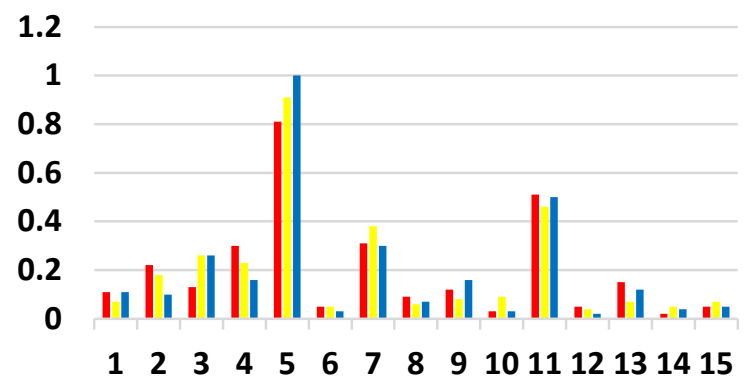

Fig 14. Voltage harmonics spectrum in circuit -2

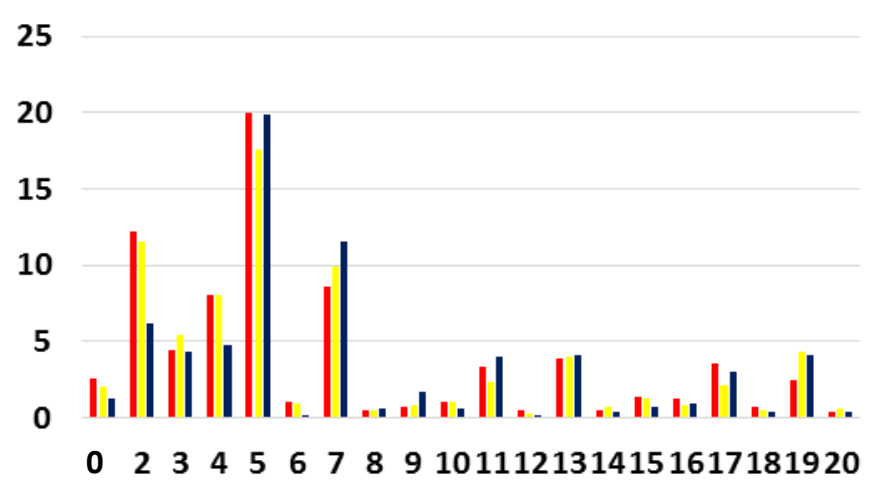

Fig 15. Current harmonics spectrum in circuit - 2

The current THD is increased from $20.46 \%$ in circuit -1 to $27.6 \%$. The voltage THD is dcreased closely from $1.54 \%$ to $1.35 \%$. The individual harmoincs order is following the same in circuit -1 . The harmonics order predominantly present in current are 2, 3, 4, 5, 7, 11 and 13 and above $4 \%$.
Circuit Condition: 3

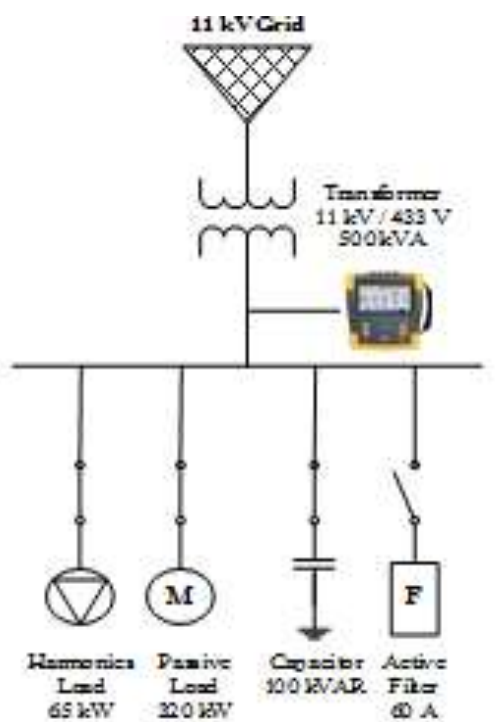

Fig 16. Single Line Diagram for circuit -3

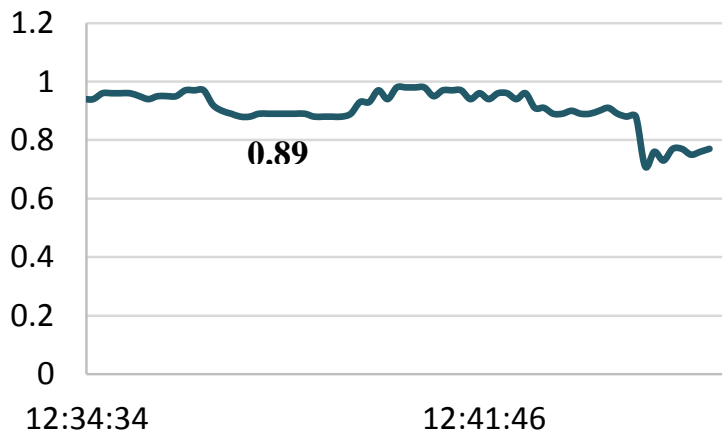

Fig 17. Power factor trend in circuit - 3

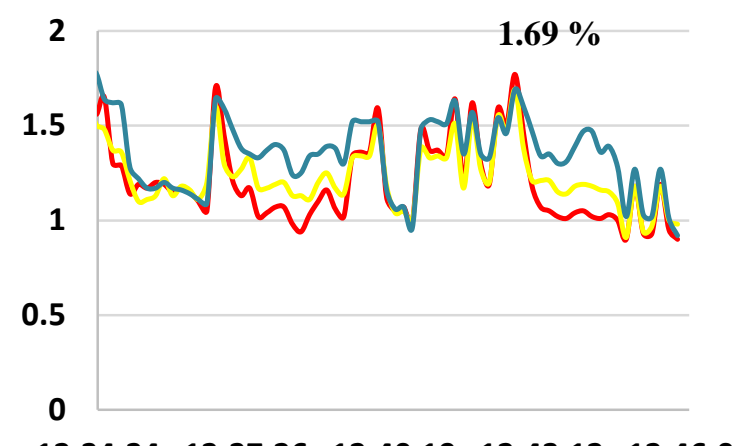

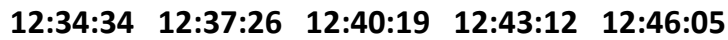

Fig 18. Voltage THD trend in circuit - 3 


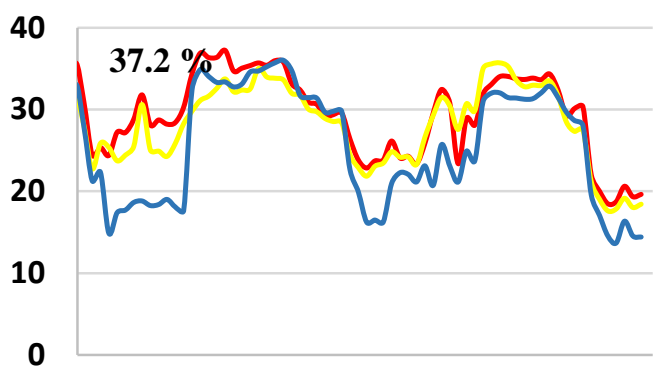

12:34:34 12:37:26 12:40:19 12:43:12 $12: 46: 05$

Fig 19. Currennt THD trend in circuit -3

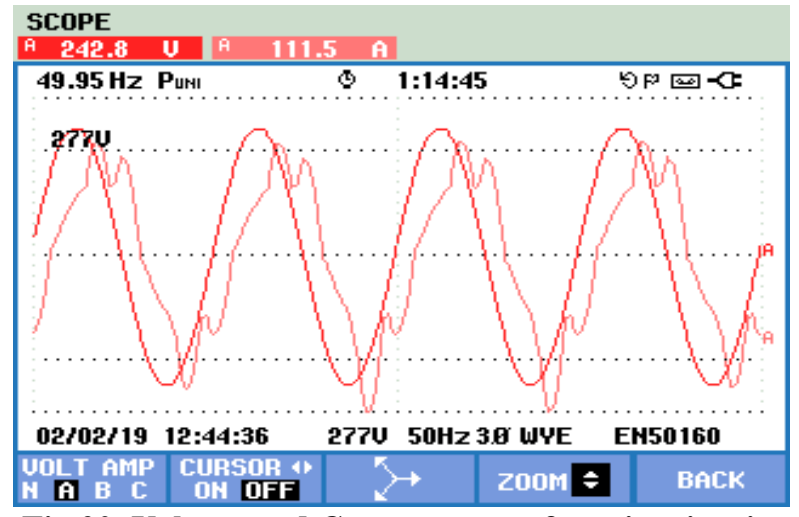

Fig 20. Voltage and Currennt waveform in circuit - 3

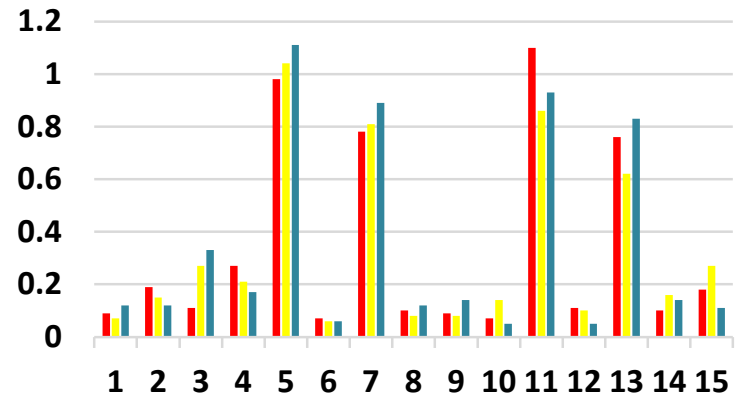

Fig 21. Voltage harmonics spectrum in circuit - 3

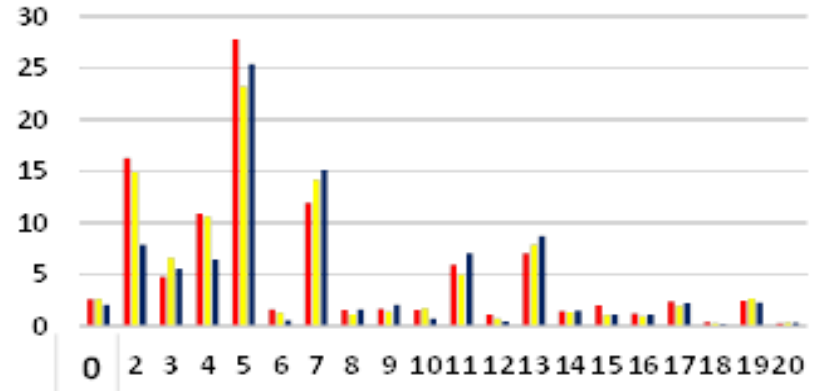

Fig 22. Current harmonics spectrum in circuit - 3

The voltage THD and current THD are increased to $1.69 \%$ and $37.2 \%$ due to filter is OFF. The current waveform is highly distorted. The harmoncs orders are 2, 3, 4, 5, 7, 11, 13 are above $5 \%$.
Circuit Condition: 4

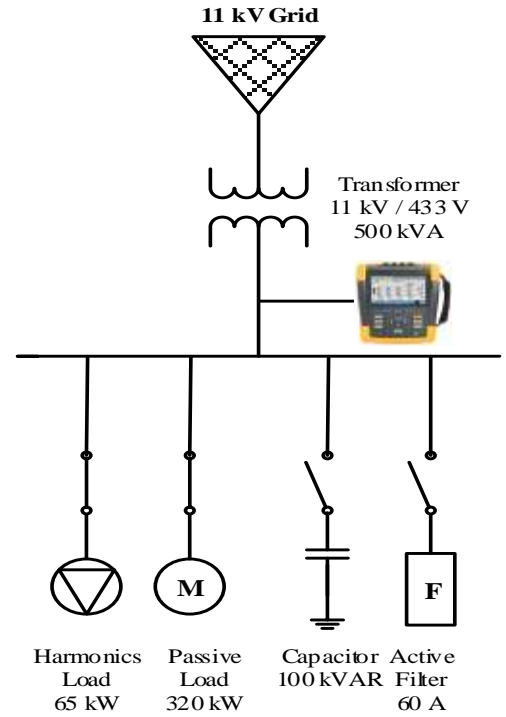

Fig 23. Single Line Diagram for circuit - 4

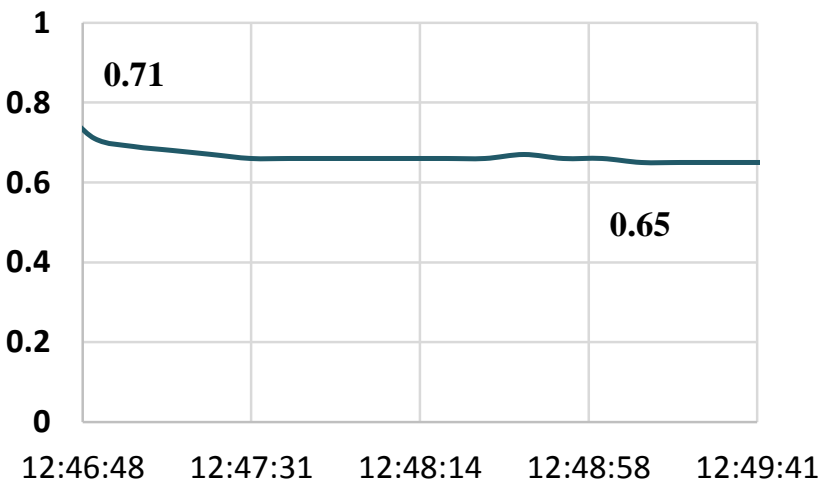

Fig 24. Power factor trend in circuit - 4

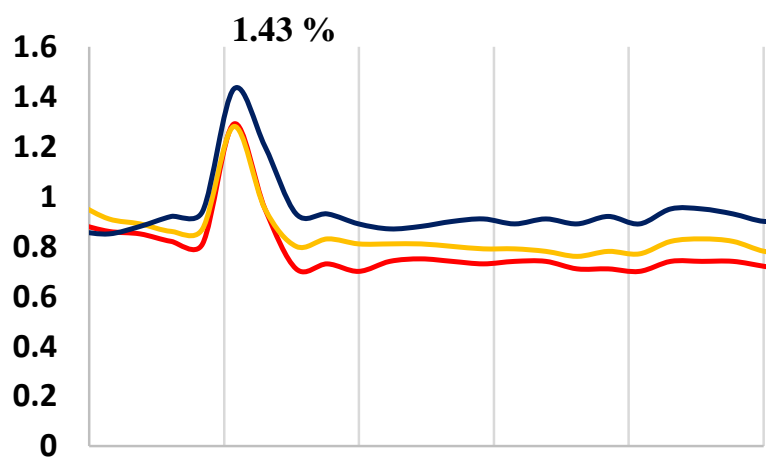

12:46:05 12:46:48 12:47:31 12:48:14 12:48:58 12:49:41

Fig 25. Voltage THD trend in circuit - 4 


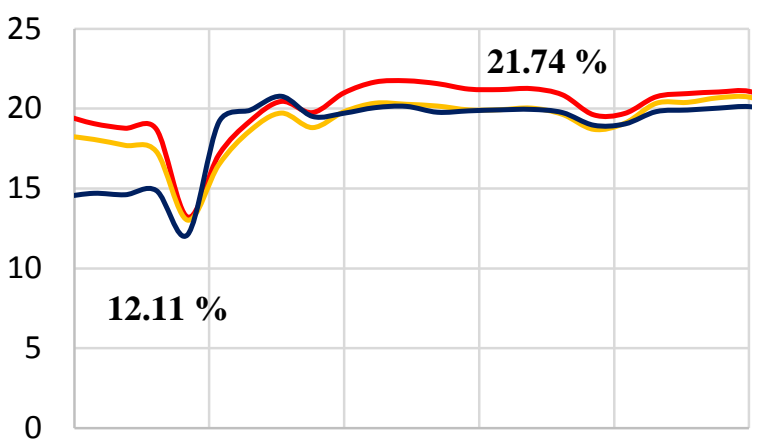

12:46:05 12:46:48 12:47:31 12:48:14 12:48:58 12:49:41

Fig 26. Current THD trend in circuit -4

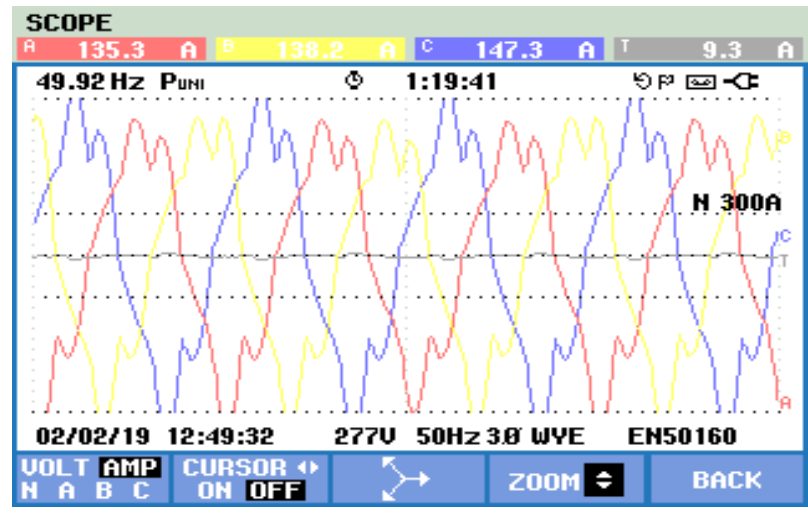

Fig 27. Three-phase current wavefrom in circuit - 4

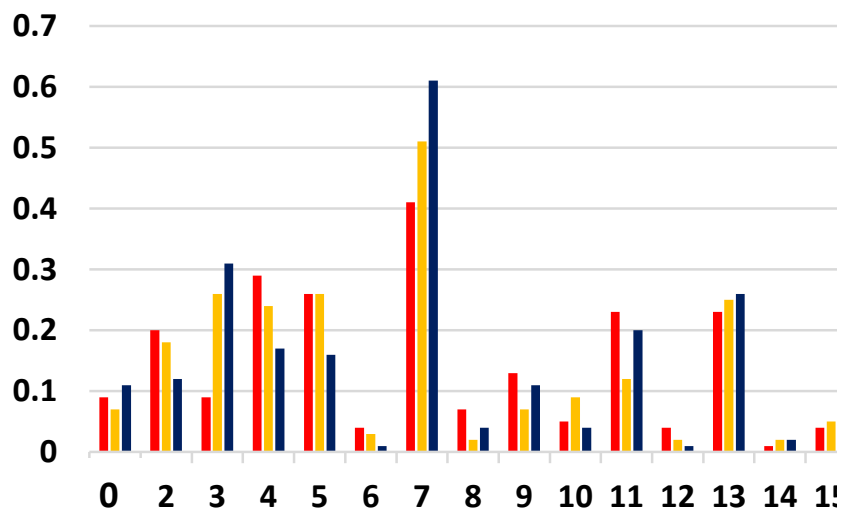

Fig 28. Voltage spectrum in circuit - 4

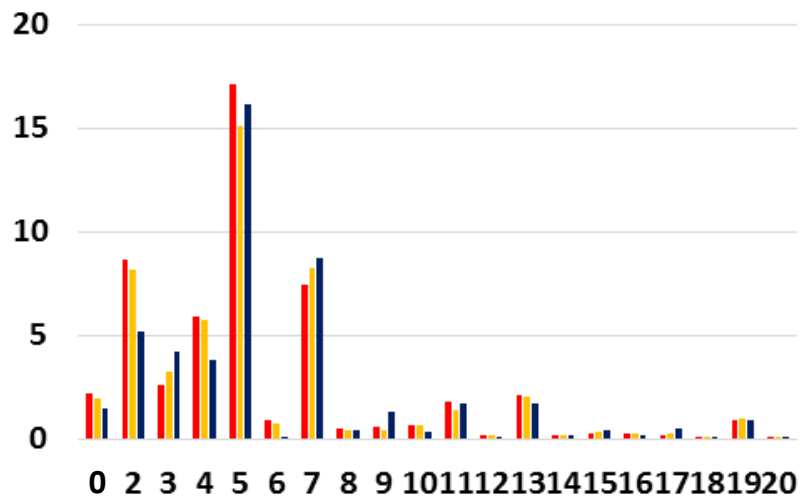

Fig 29. Current spectrum in circuit - 4
Fig.23 shows the power factor is highly fluctauating between 0.63 and 0.75 due to both the capacitor and filter being OFF. From Fig $24 \& 25$, the voltage THD is similar to the circuit where capacitor OFF was observed. And the current THD is varying between $20.12 \%$ and $5.32 \%$ as the active filter and capacitor are both OFF. The individual harmonics orders found to be 2, 3, 4, 5, 7 are above $4 \%$ from Fig 28. Fig. 26 shows that the three-phase current waveforms are highly distorted as the active filter is OFF.

\section{Unbalanced current}

The Unbalanced analysis was done and the results are displayed.

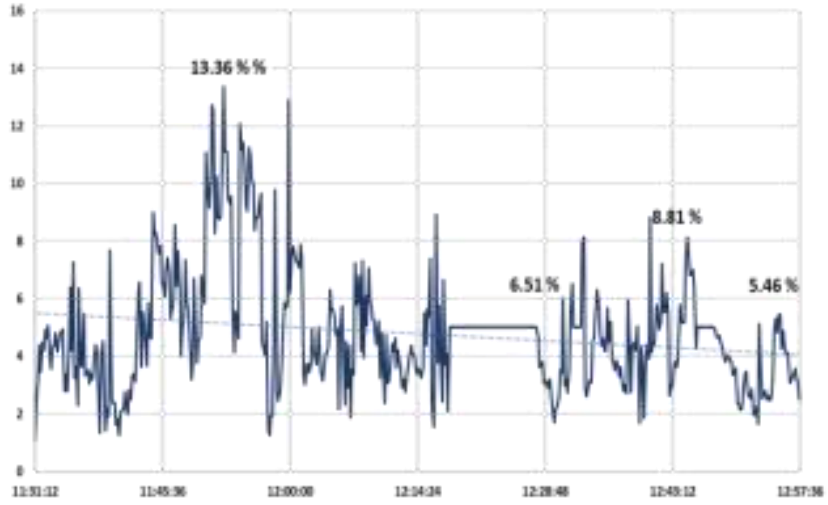

Fig 30. Unbalanced Current at four circuit conditions

The amount of unbalance current under normal circuit condition -4 is $10.42 \%$. This is due to the number of single phase loads connected into the circuit at the moment. At circuit condition - 3 the harmonics filter reduce the unbalance by $7 \%$ as a result of dynamic compensation of reactive power. The circuit condition -2 increased due to capacitors aggravating the unbalance by charging current. The circuit conidition -1 is $4.74 \%$ when the filter and capacitors are OFF.

\section{HARMONICS LOAD}

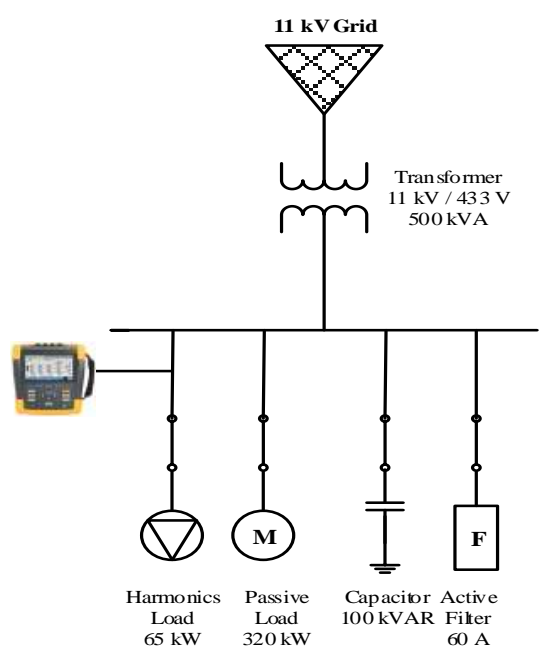

Fig 31. Harmonic Load Measurement

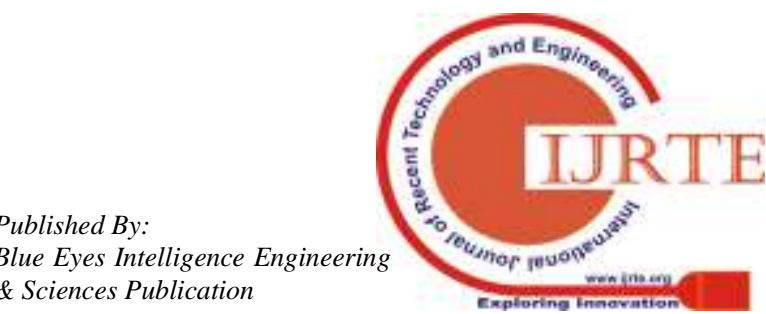


Linomatic NOVA RB104

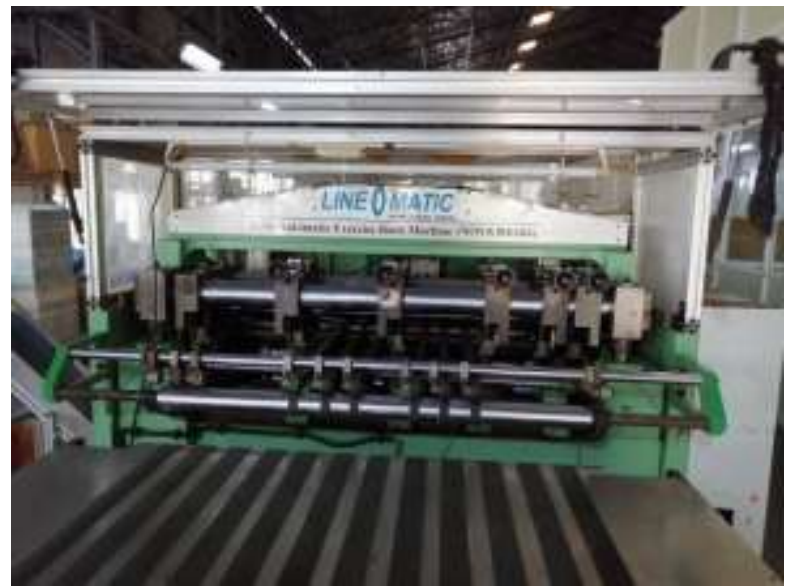

Fig 32. Linomatic RB104 installed at the industry

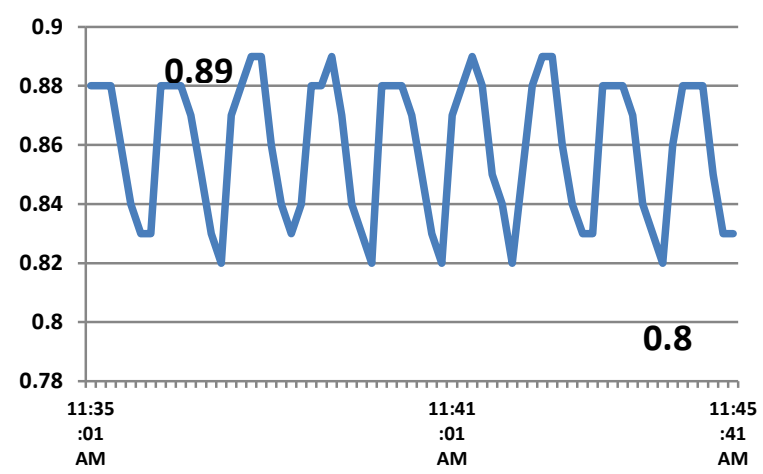

Fig 33. Power Factor Trend

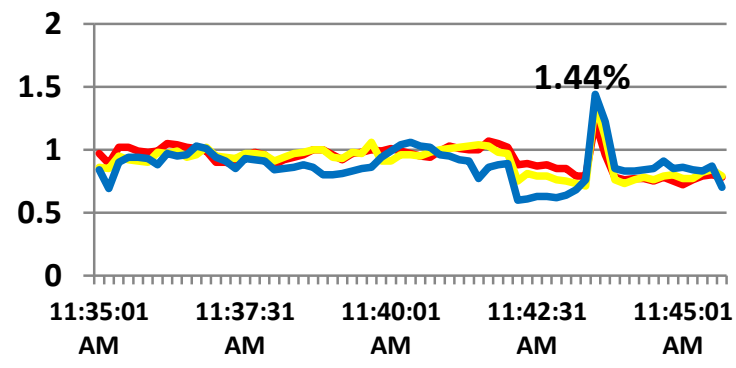

Fig 34. Voltage THD Trend

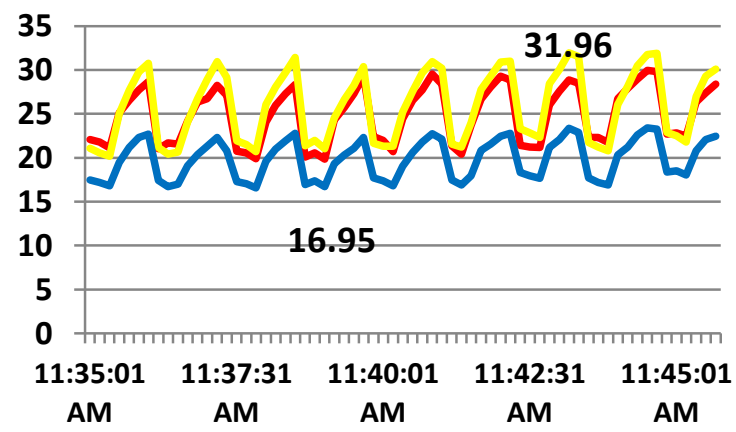

Fig 35. Current THD Trend

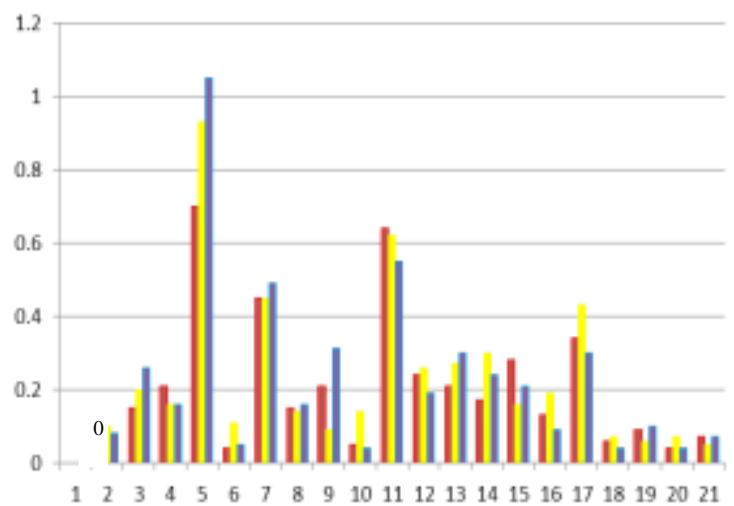

Fig 36. Voltage Harmonics Spectrum

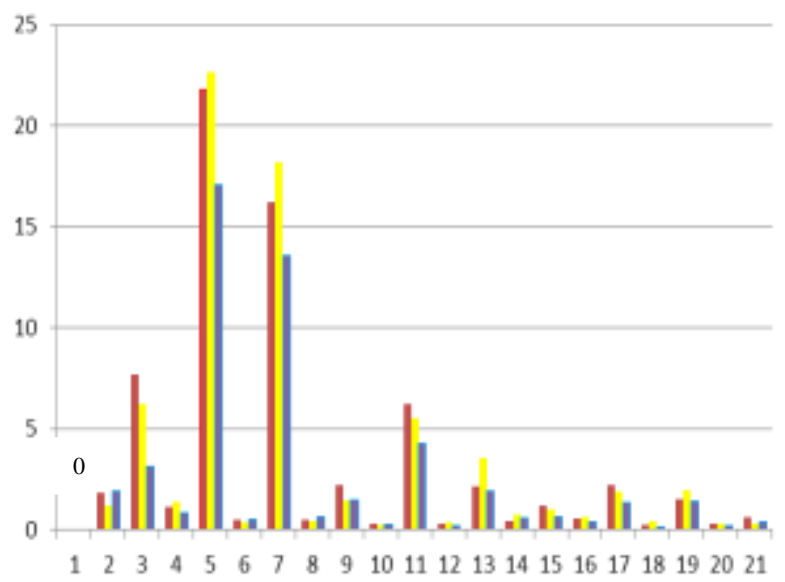

Fig 37. Current Harmonics Spectrum

The power factor varies at loading from 0.82 to 0.89 . The Voltage THD and Current THD are recorded as $1.44 \%$ and $31.96 \%$ respectively. The predominant Harmonic Orders are found to be $3,5,7,9,11,13$.

Heidelberg SM74

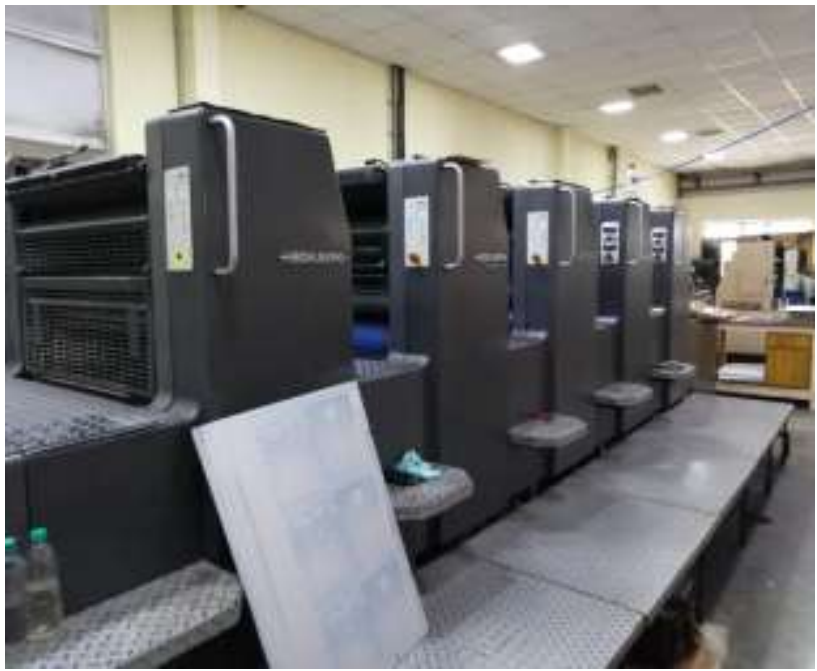

Fig 38. Heidelberg SM74 installed at the industry 


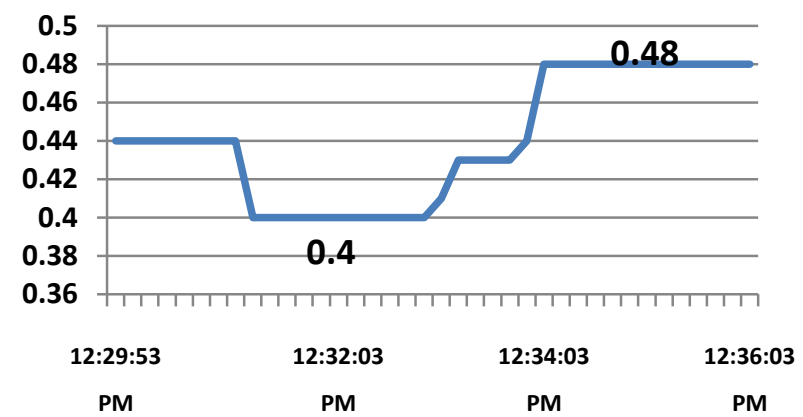

Fig 39. Power Factor Trend

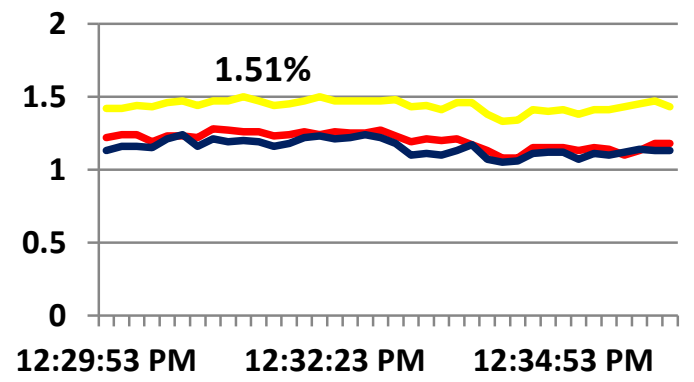

Fig 40. Voltage THD Trend

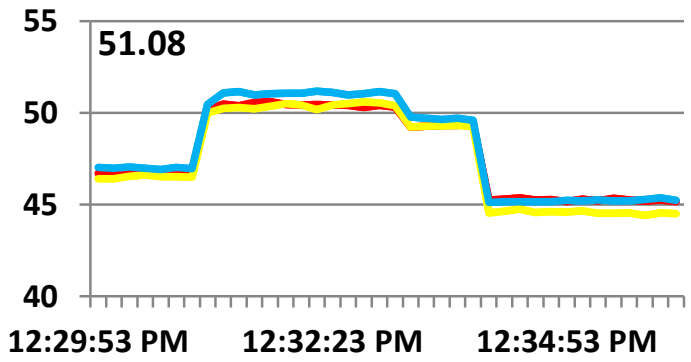

Fig 41. Current THD Trend

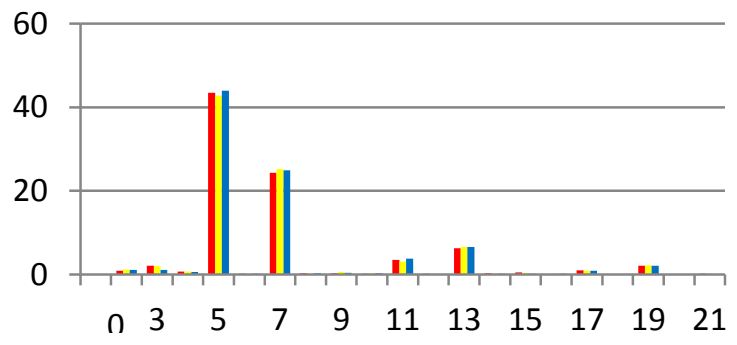

Fig 42. Current Harmonics Spectrum

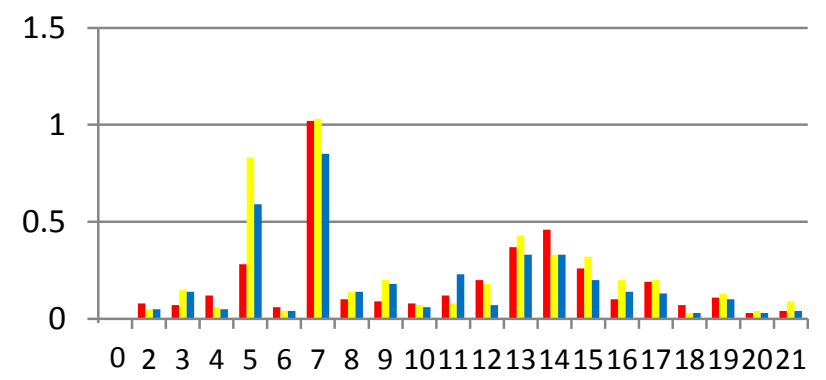

Fig 43. Voltage Harmonics Spectrum

The power factor varies at loading from 0.4 to 0.48 . The Voltage THD and Current THD are recorded as $1.51 \%$ and $51.08 \%$ respectively. The predominant Harmonic Orders are found to be $3,5,7,9,11,13$.

\section{VERIFICATION OF IEEE 519-1992 \& RESULTS}

$\mathrm{I}_{\mathrm{sc}}$ Calculation was done based on the maximum demand reached in the industry for the past one year as $132 \mathrm{KVA}$.

$\mathrm{I}_{\mathrm{L}}$ is noted from the current reading at the time of circuit condition 1 as $127 \mathrm{~A}$.

The corresponding $\mathrm{I}_{\mathrm{sc}} / \mathrm{I}_{\mathrm{L}}$ is referred in IEEE-519-1992 [5] table for current distortion limits. This is referred in the first row of the table for TDD (Total Demand Distortion, which is defined by the ratio of total harmonic distortion current and the fundamental harmonic current [4]) as 5\%. Because of the difference between $\mathrm{I}_{1}$ and $\mathrm{I}_{\mathrm{L}}$, it is determined as $7.5 \%$ as a THD limit with respect to the standard. The richness of the current harmonics noticed as $20.46 \%$ in circuit condition - 1 which is more than the the permitted level. The voltage harmonics are well within the limit.

\begin{tabular}{|c|c|c|c|c|c|c|}
\hline \multicolumn{7}{|c|}{ Msimum Hammsnc Oument Diststion in Percent of t. } \\
\hline \multicolumn{7}{|c|}{ Rdvisual Hamsnic Order (Odd Hasnonics) } \\
\hline level & सा & $11 s<<17$ & $17: 23$ & $23 \sin 35$ & $35: h$ & $T D D$ \\
\hline$\angle a^{\prime}$ & 40 & 20 & 15 & 0.6 & 0.3 & 50 \\
\hline $20<50$ & 70 & 35 & 25 & 10 & 0.5 & 80 \\
\hline $5 \times 105$ & 100 & 45 & 40 & 1.5 & 0.7 & 120 \\
\hline $100 \times 1080$ & 120 & 55 & 50 & 20 & 1.0 & 150 \\
\hline 31020 & 150 & 70 & 60 & 25 & 1.4 & 200 \\
\hline \multicolumn{7}{|c|}{ Even hamorics are limited to $25 \%$ of the odt hamonic imits above. } \\
\hline \multicolumn{7}{|c|}{ Dament distortions that resut in a de otset a.g halt-nave ochierters, are not alowet. } \\
\hline \multicolumn{7}{|c|}{ 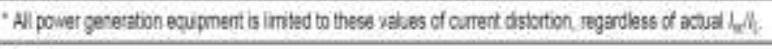 } \\
\hline \multicolumn{7}{|l|}{ Whare } \\
\hline le & \multicolumn{6}{|c|}{$=$ mactium shon-cioul cutrent at $P C C$. } \\
\hline$t$ & \multicolumn{6}{|c|}{ 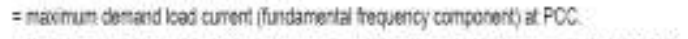 } \\
\hline TDO & \multicolumn{6}{|c|}{ 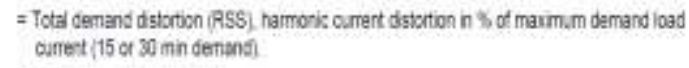 } \\
\hline PCC & \multicolumn{6}{|c|}{$=$ Point d comron coupling } \\
\hline
\end{tabular}

Table .2 IEEE-519-1992 for current harmonics

\section{CONCLUSION}

The Harmonic characteristics of the specific loads used in the printing industry are studied. They are compared with the harmonic readings taken at LV side of the transformer. It is found to be having the same Harmonic Orders $(3,5,7,9,11,13)$. The Harmonic patterns are verified with LV side measurement and found to be equivalent. The capacitors used for improving Power Factor are intensively aggravating the individual harmonics. The rating of active filter installed is inadequate to compensate for the varying harmonic loads. The $2^{\text {nd }}$ order harmonics recorded, is due to the partial loading of transformer resulting in an increase in reactive current. This increase also needs to be compensated by the suitable selection of harmonics to be eliminated by the active filter.

This paper will present an idea about the unique harmonic pattern of large capacity offset machines used in printing industry and also these datas will help to perform harmonic analysis with respect to source impedence. 


\section{REFERENCES}

1 Ritchie Pragale, Thomas J. Dionise, and David D. Shipp, Haitao $\mathrm{Hu}$, Yang Shao, Li Tang, Jin Ma, Zhengyou He, ,Shibin Gao "Harmonic Analysis and Multistage Filter Design for a Large Bleach Production Facility," IEEE Transactions on industry applications, vol. 47, No. 3, May / June 2011

2 J.P.Nelson, "A better understanding of harmonic distortion in the petrochemical industry," IEEE Trans. Ind. Applications, vol.40, No.1, Jan. /Feb. 2004

3 V.Suresh Kumar, V.Saravanan and P.S Kannan, "Harmonic distortion in a modern cement industry - A case study", in Proc. IEEE Power Engineering, New Delhi, 10-12, April 2006.

4 Wakileh G.J., "Power System Harmonics",Springer-Verlag, Berlin, 2001.

5 G.W. Chang, Y.J. Liu, H.M. Huang, S.Y. Chu, "Harmonic Analysis of the Industrial Power System with an AC Electric Arc Furnace". Power Engineering Society General Meeting 2006 (IEEE 18-22 June 2006).

6 T. M. Blooming, D. J. Carnovale, "Application of IEEE Std. 519-1992 harmonic limits", Pulp and Paper Industry Technical Conference 2006. Conference Record of Annual, pp. 1-9, 2006. 